\title{
YKL-40 correlates with the phenotype of asthma
}

\author{
Krzysztof Specjalski, Ewa Jassem \\ From 3rd WAO International Scientific Conference (WISC) 2014 \\ Rio de Janeiro, Brazil. 6-9 December 2014
}

\section{Background}

YKL-40 is a chitinase-like protein synthesized by human macrophages, monocytes, and neutrophils. Although it is not specific, YKL-40 has been shown to correlate with asthma, its severity and level of control. As asthma is heterogeneous, it would be useful to determine whether the marker's levels correlate with phenotypes of the disease. The aim of the study was to investigate the relevance of YKL-40 as a biomarker of asthma phenotype.

\section{Methods}

Level of YKL-40 was determined by means of immunoassay in sera of 167 asthmatics (116 women, 51 men; aged 18-88; mean age: 49 years) and 81 healthy controls (50 women, 31 men; aged 18-86; mean age: 48 years). On the basis of clinical criteria asthmatics were divided into four groups: atopic -83 patients, non-atopic -63 , aspirin asthma - 12, asthma with underlying vasculitis9. Differences between groups were compared with the use of U-Mann-Whitney's test. Correlations between variables were assessed with Pearson's test.

\section{Results}

YKL-40 levels were significantly higher, on average, in asthmatics compared to control group (mean levels: 66,8 $\mathrm{U} / 1$ and 44,9 $\mathrm{U} / \mathrm{l}$ respectively; $\mathrm{p}<0,001)$. YKL-40 correlated with lack of asthma control $(\mathrm{p}<0,001)$ and diagnosis of exacerbation $(\mathrm{p}<0,001)$. The highest mean concentration was found in atopic asthmatics $-72 \mathrm{U} / \mathrm{l}$ which was significantly higher compared to non-atopic patients -61 $\mathrm{U} / \mathrm{l}(\mathrm{p}<0,05)$. Weak correlations were found between

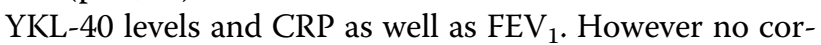
relations have been found between YKL-40 level and sex, blood eosinophils count and neutrophils count.

\section{Conclusions}

YKL-40 correlates with asthma control, atopy, $\mathrm{FEV}_{1}$ and CRP. The latter suggests that YKL-40 concentration

Medical University of Gdansk, Poland (http://creativecommons.org/publicdomain/zero/1.0/) applies to the data made available in this article, unless otherwise stated. 